\title{
Diagnóstico post mortem de tripanosomiasis canina usando la Reacción en Cadena de la Polimerasa
}

\section{Post Mortem Diagnosis of Canine Trypanosomiasis Using the Polymerase Chain Reaction Diagnóstico post mortem de tripanossomíase canina usando a Reação em Cadeia da Polimerase}

Andrea Urbina ${ }^{1} \bowtie$, Juan Alberto Morales $^{2}$, Diana Vargas ${ }^{1}$, María Méndez ${ }^{2}$, Milena Argüello ${ }^{1,3,4}$, Silvia Acevedo $^{1}$, Luis Ricardo Corrales ${ }^{1}$, Alejandro Alfaro ${ }^{2}$

1 Laboratorio de Zoonosis, Escuela de Medicina Veterinaria, Universidad Nacional, Heredia, Costa Rica. E-mail: andreaurbina3@gmail.com; v.g.diana3@gmail.com; milenaarguellos@gmail.com; $\underline{\text { silacegon@gmail.com; xrichard18@gmail.com }}$

2 Laboratorio de Patología, Escuela de Medicina Veterinaria, Universidad Nacional, Heredia, Costa Rica. E-mail: juan.alberto. morales.emv@gmail.com; mokomaria@gmail.com; alejandro.alfaro.alarcon@una.cr

3 Awá Science \& Conservation, Costa Rica. Email: milenaarguellos@gmail.com

4 Laboratorio de Ecología de Enfermedades y Una Salud, Facultad de Medicina Veterinaria y Zootecnia, Universidad Nacional Autónoma de México, México. Email: milenaarguellos@gmail.com

Recibido: 3 de noviembre de 2020 Corregido: 12 de mayo de 2020 Aceptado: 21 de mayo de 2021

\begin{abstract}
Resumen
El objetivo de este estudio fue utilizar la reacción en cadena de la polimerasa (PCR) para detectar $\mathrm{ADN}_{\mathrm{k}}$ de Trypanosoma cruzi en tejidos cardíacos embebidos en parafina de 18 perros con miocarditis con muerte súbita y/o con signos sugestivos de tripanosomiasis. La PCR resultó positiva en 7 perros con nidos de amastigotos de T. cruzi y en 11 sin evidencia de parásitos. Se describen los hallazgos clínicos y patológicos en estos caninos.
\end{abstract}

Palabras clave: Trypanosoma cruzi, perros, histopatología, PCR

\begin{abstract}
This study aimed to detect Trypanosoma cruzi kDNA from paraffin-embedded cardiac tissue in eighteen dogs with myocarditis which presented sudden death and /or signs suggestive of canine trypanosomiasis. The PCR was positive in 7 dogs with myocarditis and amastigotes of T. cruzi and in 11 dogs with myocarditis but with no evidence of parasites. Clinical and pathological findings in these canines are described.
\end{abstract}

Keywords: Trypanosoma cruzi, dogs, histopathology, PCR

\section{Resumo}

O objetivo deste estudo foi usar a reação em cadeia da polimerase (PCR) para detectar o kDNA do Trypanosoma cruzi em tecidos cardíacos, embebidos em parafina, de 18 cães com miocardite, com morte súbita e / ou sinais sugestivos de tripanossomíase. $\mathrm{O}$ resultado do exame de PCR foi positivo em sete cães com ninhos de amastigotas de T. cruzi e em 11 sem evidência de parasitas. Os achados clínicos e patológicos nesses caninos são descritos.

Palavras-chave: Trypanosoma cruzi, cães, histopatologia, PCR

$\bar{\otimes}$ Autor de correspondencia: andreaurbina3@gmail.com

(c) $(1) \odot \begin{aligned} & \text { Licencia Creative Commons } \\ & \text { Atribución-No-Comercial }\end{aligned}$ BY NC ND SinDerivadas 3.0 Costa Rica
Stribución-No-Comerial
Andrea Urbina, Juan Alberto Morales, Diana Vargas, María Méndez, Milena Argüello, Silvia Acevedo, Luis Ricardo Corrales, Alejandro Alfaro 


\section{Introducción}

La tripanosomiasis americana es una enfermedad parasitaria zoonótica causada por el protozoario Trypanosoma cruzi y transmitida a mamíferos silvestres y domésticos principalmente por insectos triatominos (Cantillo-Barraza et al., 2015). Los perros se consideran reservorios domésticos importantes en el continente americano (Barr et al., 1989; Meyers et al., 2017); además es posible que al infectarse desarrollen enfermedad cardíaca con o sin signos clínicos al igual que los humanos (Eloy \& Lucheis, 2009; Sykes \& Greene, 2013). Los perros tienen un mayor riesgo de infección por T. cruzi que los humanos (Balan et al., 2011) y pueden sufrir muerte súbita antes de que se logre establecer un diagnóstico presuntivo (Vitt et al., 2016). El diagnóstico post mortem se basa en el hallazgo histológico de cardiomiocitos con pseudoquistes que contienen amastigotos (Vitt et al., 2016); sin embargo, su sensibilidad es baja debido a la variación natural en el número y distribución de amastigotos en las secciones de tejido y según la etapa de infección de la enfermedad. Por lo cual, los pseudoquistes son con frecuencia difíciles de encontrar (Barr et al., 1989) y se generan diagnósticos histopatológicos falsos negativos. La prueba de PCR es una herramienta altamente sensible y específica para el diagnóstico de tripanosomiasis humana y animal (Ferrer, 2015; Moser et al., 1989; Williams et al., 2009). Puede detectar el $\mathrm{ADN}_{\mathrm{k}}$ de T. cruzi en diferentes muestras biológicas, incluidos tejidos frescos o fijados con formalina (Greer et al., 1991; Jones et al., 1993; Williams et al., 2009). Son muy escasos los estudios de tripanosomiasis en caninos empleando métodos de diagnóstico molecular (Lizundia et al., 2014) y tampoco estas pruebas se han utilizado como apoyo diagnóstico post mortem en perros. El objetivo de este estudio fue determinar la presencia de $\mathrm{ADN}_{\mathrm{k}}$ de T. cruzi mediante la prueba de PCR en tejido cardiaco parafinado de caninos con miocarditis con muerte súbita y/o con signos sugestivos de tripanosomiasis.

\section{Materiales y Métodos}

Se realizó una revisión retrospectiva de los registros de todos los perros sometidos a estudios post mortem entre 1987 y 2018 en el Laboratorio de Patología de la Escuela de Medicina Veterinaria de la Universidad Nacional de Costa Rica. Los criterios de inclusión para el análisis mediante PCR fueron: muerte súbita, ascitis, historial de trastornos en ritmo cardiaco, hallazgos morfológicos sugestivos de etiología chagásica (miocarditis granulomatosa, necrosis miocárdica, inflamación linfoplasmocitaria con pérdida extensa de fibras miocárdicas o fibrosis intersticial severa) con o sin presencia de pseudoquistes con amastigotos (Caliari et al., 2002; Vitt et al., 2016). Para la extracción de ADN del tejido cardiaco embebido en parafina se seleccionaron 18 casos con al menos una de las características anteriormente mencionadas. Como controles positivos se utilizaron muestras de tejido cardiaco embebido en parafina de ratones infectados experimentalmente con una cepa de T. cruzi aislada de un perro con infección natural y caracterizada como TcI (Mena-Marín et al., 2012). Como controles negativos se utilizaron tejidos cardíacos embebidos en parafina de ratones sanos. La desparafinación de los tejidos se realizó según lo descrito previamente (Greer et al., 1991)con algunas modificaciones. Se realizaron cortes a cada bloque y se eliminaron los bordes de parafina obteniéndose 25 mg de cada tejido cardiaco que se colocaron en un tubo de microcentrífuga estéril de $1.5 \mathrm{ml}$. El micrótomo y la cuchilla se limpiaron con xilol entre un bloque de parafina y otro. Cada tejido se mezcló con $500 \mu l$ de xilol durante 8 minutos. Luego de eliminar el xilol se hicieron dos lavados, uno con etanol al 95\% y otro con etanol al 70\% durante 5 minutos cada uno. Los sedimentos se secaron a $80{ }^{\circ} \mathrm{C}$ durante 8 min sobre un bloque de calor. La extracción total de ADN del material parafinado se realizó utilizando un kit comercial 
(QIAmp DNA Mini Kit® QIAGEN) siguiendo las instrucciones del fabricante. Se realizó una PCR convencional utilizando el set de cebadores S35 (5’AAATAAT GTACGGGTGGAGATGCATGA-3') y S36 (5'-GGGTTCGATTGGGGTTGGTGT-3'). Estos iniciadores amplifican un fragmento de 330 pb derivado de la región variable de los minicírculos de T. cruzi (Avila et al., 1993; Ferrer, 2015). La PCR se realizó como ha sido descrita (Rojas-Jiménez et al., 2021).

\section{Resultados}

Se evaluaron mediante PCR las muestras de 18 perros con al menos alguno de los criterios de inclusión. La totalidad de las muestras resultaron positivas a la prueba de PCR al obtenerse el producto de $330 \mathrm{pb}$. De estos animales, 9 eran hembras y 9 machos. Asimismo, 11 fueron perros de razas grandes, 2 caninos fueron de razas medianas y 2 de razas pequeñas; en 3 casos no se especificó la raza. Diez de los casos fueron perros $\leq 1$ año, 6 con edades entre 1-6 años, uno de 8 años, y uno sin edad especificada. De la historia clínica se encontró que 8 perros sufrieron muerte súbita, 3 presentaron ascitis, uno taquicardia, uno ehrlichiosis y otro enfermedad renal (Cuadro 1). Dentro de las alteraciones macroscópicas cardiacas observadas estuvieron cardiomegalia, hidropericardio, dilatación cardiaca, hipertrofia cardiaca, necrosis y hemorragias (Fig.1). En 4 de los casos no existía información clínica, sin embargo, presentaron cambios inflamatorios cardiacos sin evidencia de pseudoquistes o amastigotos de T. cruzi (Fig. 2a).

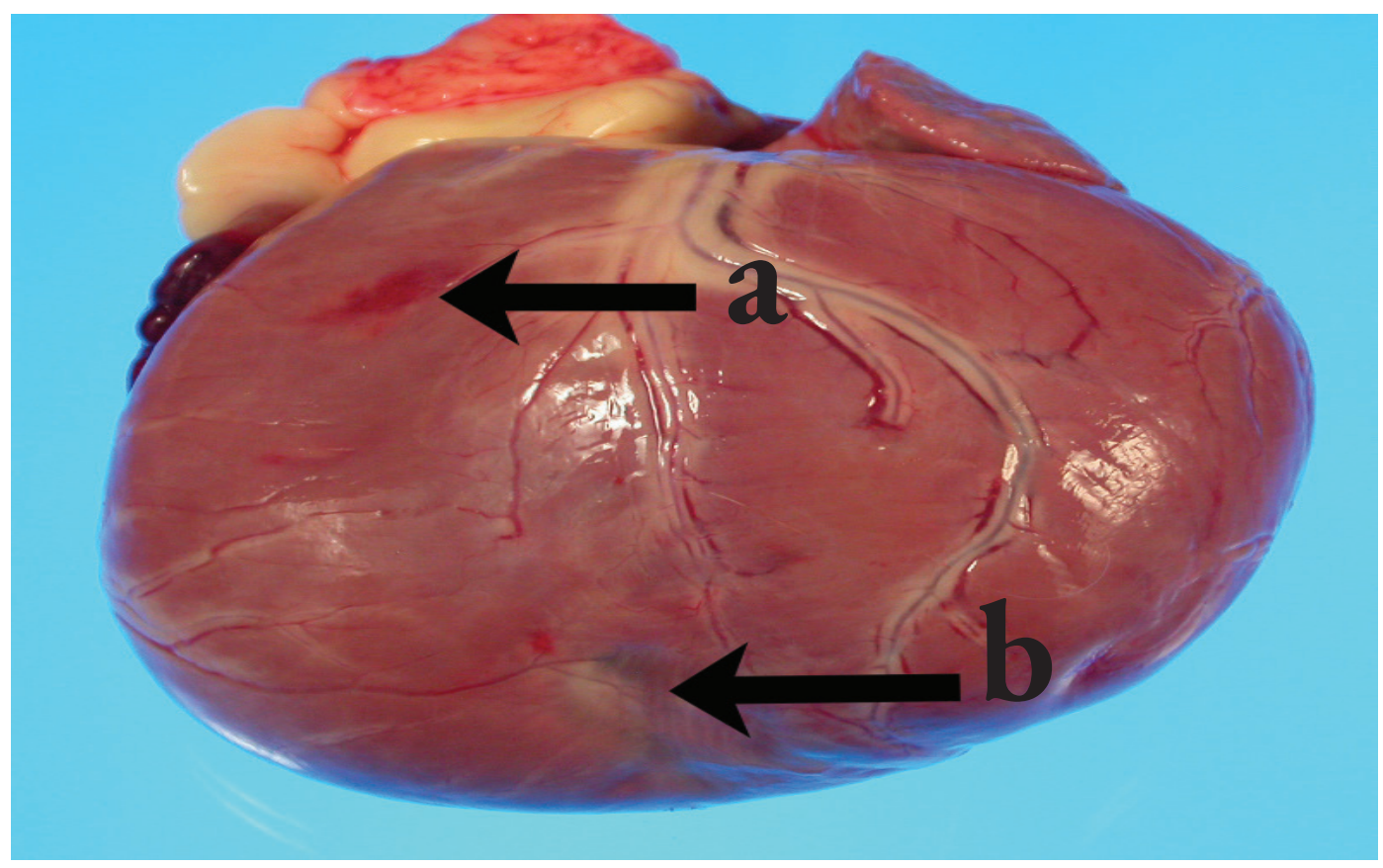

Figura 1. Corazón, epicardio ventricular derecho con focos de necrosis tisular y hemorragias (flechas). Fotografía por los autores. 
El análisis histopatológico del tejido cardiaco evidenció en 7 de los 18 casos, la presencia de nidos de amastigotos (Fig. 2 b), con escasos a abundantes parásitos en conjunto con una miocarditis linfohistioplasmocitaria (Fig. 3 a, b) en 15 casos y granulomatosa en 3 de los 18. El grado de inflamación fue severo en la mayoría de los casos (13/18), moderado (3/18) y leve (2/18). De los 13 casos con inflamación severa, 11 presentaron focos de necrosis del miocardio. La distribución del infiltrado inflamatorio fue extensa en la mayoría de los casos (17/18) y solo en uno de ellos tuvo una presentación focal (Cuadro 1).

Cuadro 1. Hallazgos clínicos e histopatológicos en 18 caninos con miocarditis y PCR positiva a Trypanosoma cruzi

\begin{tabular}{|c|c|c|c|c|c|c|}
\hline \multirow{2}{*}{ Caso } & \multirow{2}{*}{ Raza } & \multirow{2}{*}{ Edad } & \multirow{2}{*}{ Sexo } & \multirow{2}{*}{ Anamnesis } & \multicolumn{2}{|c|}{ Hallazgos morfológicos del tejido cardiaco } \\
\hline & & & & & Características de la inflamación & Amastigotos \\
\hline 1 & Doberman & $1 \mathrm{a}$ & $\mathrm{H}$ & ND & $\begin{array}{l}\text { Linfohistioplasmocitaria necrotizante multifocal } \\
\text { extensiva severa con fibrosis }\end{array}$ & $\mathrm{P}$ \\
\hline 2 & SRD & $9 \mathrm{~m}$ & $\mathrm{H}$ & ND & Granulomatosa multifocal extensiva severa & $\mathrm{P}$ \\
\hline 3 & Boxer & $4 \mathrm{a}$ & M & MS & $\begin{array}{l}\text { Linfohistioplasmocitaria necrotizante multifocal } \\
\text { extensiva severa }\end{array}$ & $\mathrm{P}$ \\
\hline 4 & Boxer & $4 \mathrm{a}$ & $\mathrm{H}$ & Ascitis & $\begin{array}{l}\text { Linfohistioplasmocitaria necrotizante multifocal } \\
\text { extensiva severa }\end{array}$ & $\mathrm{P}$ \\
\hline 5 & $\begin{array}{l}\text { Pinsher min- } \\
\quad \text { iatura }\end{array}$ & $3 \mathrm{~m}$ & M & Ascitis & Linfohistioplasmocitaria multifocal extensiva severa & $\mathrm{P}$ \\
\hline 6 & Rottweiler & $8 \mathrm{~m}$ & M & MS & Linfohistioplasmocitaria multifocal extensiva severa & $\mathrm{P}$ \\
\hline 7 & Doberman & $8 \mathrm{~m}$ & M & MS & $\begin{array}{l}\text { Granulomatosa necrotizante multifocal extensiva } \\
\text { severa }\end{array}$ & $\mathrm{P}$ \\
\hline 8 & Pastor Alemán & $3 a$ & $\mathrm{H}$ & MS & Linfohistioplasmocitaria multifocal extensiva severa & $\mathrm{A}$ \\
\hline 9 & $\begin{array}{l}\text { Golden Re- } \\
\text { triever }\end{array}$ & $5 \mathrm{~s}$ & $\mathrm{H}$ & MS & $\begin{array}{l}\text { Linfohistioplasmocitaria necrotizante multifocal } \\
\text { extensiva severa con fibrosis }\end{array}$ & A \\
\hline 10 & Rottweiler & $5 \mathrm{a}$ & M & MS & $\begin{array}{l}\text { Linfohistioplasmocitaria necrotizante multifocal } \\
\text { extensiva severa con fibrosis }\end{array}$ & $\mathrm{A}$ \\
\hline 11 & Boxer & $3 \mathrm{~m}$ & M & MS & $\begin{array}{c}\text { Linfohistioplasmocitaria necrotizante multifocal } \\
\text { extensiva severa con fibrosis }\end{array}$ & A \\
\hline 12 & Yorkshire & $2 \mathrm{a}$ & $\mathrm{H}$ & MS & $\begin{array}{l}\text { Linfohistioplasmocitaria necrotizante multifocal } \\
\text { extensiva severa con fibrosis }\end{array}$ & A \\
\hline 13 & SRD & ND & $\mathrm{H}$ & ND & $\begin{array}{l}\text { Linfohistioplasmocitaria necrotizante multifocal leve } \\
\text { con focos de fibrosis }\end{array}$ & A \\
\hline 14 & SRD & $7 \mathrm{~m}$ & $\mathrm{H}$ & Ascitis & $\begin{array}{l}\text { Linfohistioplasmocitaria necrotizante multifocal } \\
\text { extensiva severa con fibrosis }\end{array}$ & A \\
\hline 15 & San Bernardo & $8 \mathrm{a}$ & M & Ehrlichia & $\begin{array}{c}\text { Granulomatosa y necrotizante multifocal extensiva } \\
\text { moderada }\end{array}$ & $\mathrm{A}$ \\
\hline 16 & Fox Terrier & $11 \mathrm{~m}$ & M & Taquicardia & $\begin{array}{l}\text { Linfohistioplasmocitaria necrotizante focal con focos } \\
\text { de fibrosis moderada }\end{array}$ & $\mathrm{A}$ \\
\hline 17 & Basset Hound & $6 \mathrm{a}$ & M & $\begin{array}{l}\text { Enfermedad renal } \\
\quad \text { (presuntivo) }\end{array}$ & Linfohistioplasmocitaria multifocal extensiva moderada & A \\
\hline 18 & Pastor Alemán & $5 \mathrm{~m}$ & $\mathrm{H}$ & Hidropericardio & Linfohistioplasmocitaria multifocal extensiva moderado & $\mathrm{A}$ \\
\hline
\end{tabular}

Edad: $\mathrm{a}=$ ańo, $\mathrm{m}=$ meses, $\mathrm{s}=$ semanas, $\mathrm{M}=$ Macho, $\mathrm{H}=$ Hembra, Anamnesis: $\mathrm{MS}=$ Muerte súbita. Presencia de pseudoquistes de amastigotos: $\mathrm{A}=$ ausentes, $\mathrm{P}=$ presentes. $\mathrm{ND}=$ No disponible 


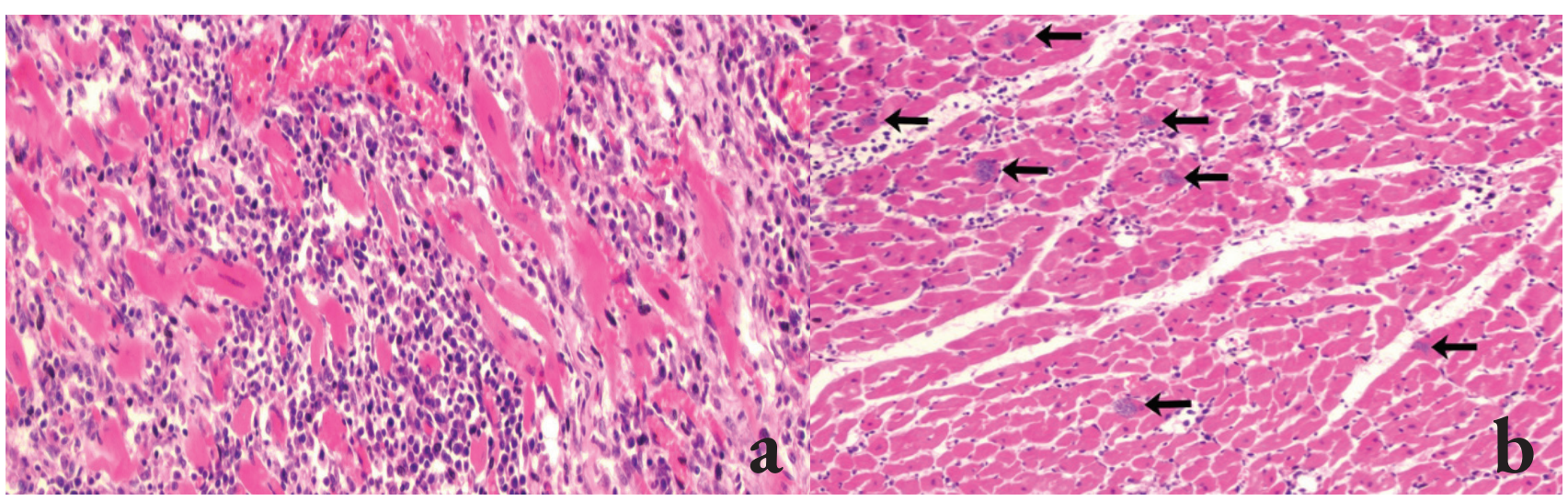

Figura 2. a) miocarditis con extensa infiltración linfohistioplamocitaria severa sin evidencia de nidos de amastigotos 200X, b) Múltiples nidos de amastigotos en fibras de miocardio (flechas) 200X. Fotografía por los autores.

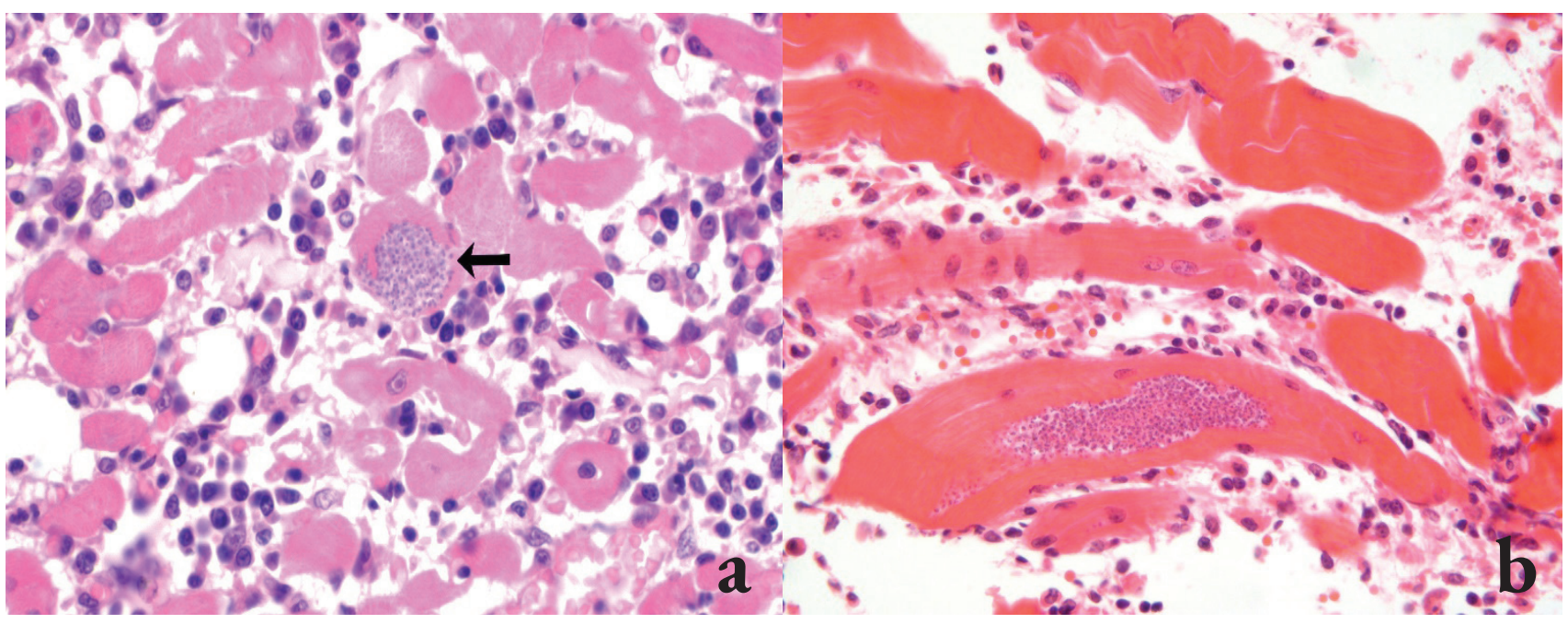

Figura 3. a) pseudoquiste con amastigotos (flecha) $600 \mathrm{X}, \mathrm{b}$ ) pseudoquiste con múltiples amastigotos dentro de cardiomiocito H\&E 600X. Fotografía por los autores.

\section{Discusión}

En todas las muestras analizadas se detectó $\mathrm{ADN}_{\mathrm{k}}$ de T. cruzi, incluyendo los 11 casos con miocarditis en los que morfológicamente no se identificó la presencia de pseudoquistes. La sensibilidad y especificidad de la prueba de PCR utilizada en este estudio ha sido demostrada en tejidos cardiacos de ratones con infección experimental aguda y crónica detectando además $\mathrm{ADN}$ de parásitos de dos diferentes linajes y también en sangre de humanos con infección crónica (Avila et al., 1993; Barrera et al., 2008). Aun cuando podría amplificar fragmentos de Trypanosoma rangeli (Vallejo et al., 1999), este tripanosomátido no es patógeno para mamíferos y no invade tejido cardiaco (Vallejo et al., 2015). Así mismo, la infección crónica natural con 
T. cruzi en pizotes (Nasua narica) de nuestro país ha sido confirmada empleando esta misma PCR en conjunto con la histopatología (Rojas-Jiménezet al., 2021). En el presente estudio, la PCR fue una herramienta importante en el diagnóstico post mortem de casos sospechosos de tripanosomiasis canina. Sin embargo, una PCR negativa no descarta la presencia del material genético del parásito (Rassi et al., 2012). Aunque en esta investigación no se identificaron las Unidades Discretas de Tipificación (DTU's) de T. cruzi, ya se ha reportado que el linaje TcI es el que está presente en caninos, marsupiales y triatominos de Costa Rica (Zuriaga et al., 2012). Los cambios histopatológicos encontrados en los perros de este estudio coinciden con los hallados en coyotes de Texas en los que la miocarditis linfoplasmocitaria estuvo asociada a TcI, genotipo a su vez asociado a la forma crónica de infección (Hodo et al., 2020). La mayoría de los casos aquí analizados presentaba una miocarditis linfohistioplasmocitaria extensa en las diferentes cámaras cardiacas, con presencia de amplios focos de necrosis en algunos de los casos. Si bien este tipo de infiltrado no es patognomónico, sí apoya el diagnóstico de infección por T. cruzi especialmente cuando es acompañado por una PCR positiva (Hodo et al., 2020). Nuestros hallazgos sugieren que la enfermedad se encontraba en la fase crónica de la infección (Caliari et al., 2002; Zachary \& McGavin, 2016). Las características del infiltrado inflamatorio con predominio granulomatoso orientaron el diagnóstico mayoritariamente a una miocarditis chagásica ya que otros agentes como Leishmania infantum, Neospora caninum, Hepatozoon canis y Toxoplasma gondii, tienden a producir daños más necrotizantes y piogranulomatosos (Molesan et al., 2019. Además, algunos de estos protozaoarios poseen características morfológicas diferentes a las de T. cruzi. La ausencia de hallazgos significativos en otros órganos hizo poco probable la presunción de otros agentes parasitarios, virales, bacterianos o agentes tóxicos. Dos de los casos analizados fueron en animales de corta edad ( 5 y 12 semanas), ambos con una miocarditis linfohistioplasmocitaria extensa severa con focos de fibrosis. Debido a la cronicidad del proceso inflamatorio se presume que la infección con T. cruzi pudo ocurrir por transmisión vectorial ya sea por la forma contaminativa, u oral por ingestión del vector infectado, vertebrados infectados o alimentos contaminados con heces del insecto conteniendo tripomastigotos metacíclicos (Eloy \& Lucheis, 2009) desde los primeros días de vida, o inclusive la infección pudo darse por vía transplacentaria o transmamaria (Barr, 2009). Estas rutas de transmisión a partir de la madre infectada podrían constituir un mecanismo de amplificación de la infección en caninos, lo cual amerita más investigación a nivel de campo. En los 8 animales en los que se reportó muerte súbita, se determinó que el grado de inflamación y la afección de las diversas cámaras cardiacas era extensa y severa con amplios cambios necrotizantes y fibróticos. La extensión y severidad de las lesiones podrían haber desencadenado la muerte súbita. En tripanosomiasis experimental canina, la fibrosis se presenta igual que la descrita en cardiopatía crónica en humanos (Caliari et al., 2002). Esto sugiere que el grado de severidad de la miocarditis o daño tisular podría ser uno de los factores relacionados con la severidad del cuadro clínico y/o muerte súbita como lo han descrito otros autores (Caliari et al., 2002; Tafuri, 1999). En cuanto a la raza, predominaron animales de razas grandes. Dicho predominio ha sido reconocido igualmente en estudios epidemiológicos de tripanosomiasis canina y se ha asociado principalmente a factores del estilo de vida y actividad de los perros de razas grandes tales como permanecer mayor tiempo en exteriores y que pueden aumentar significativamente el riesgo de exposición y contacto con vectores infectados del peridomicilio (Kjos et al., 2008; Saldaña et al., 2015). Por otra parte, es necesario destacar que en ninguno de los casos analizados existía sospecha clínica de la enfermedad de Chagas. Los hallazgos de los estudios histopatológicos post mortem junto al resultado de la PCR fueron los que establecieron el diagnóstico definitivo. Se debe señalar que a pesar de que Costa Rica es un país endémico para la tripanosomiasis canina con tasas de seroprevalencia entre 6.4\% y 23\% (Bonilla et al., 2019; Montenegro 
et al., 2002), es posible que la enfermedad sea subdiagnosticada en la práctica clínica veterinaria, lo que coincide con los hallazgos encontrados en este estudio. El no reconocimiento de la infección por T. cruzi en caninos podría relacionarse con desconocimiento de la epidemiología de la enfermedad en nuestro país, así como con su variada e inespecífica presentación clínica (Meyers et al., 2017). Al infectarse con este agente, los perros pueden sufrir la forma aguda mostrando signos no específicos como letargia, membranas mucosas pálidas, linfoadenopatía generalizada, o inclusive pueden sufrir muerte súbita como único signo clínico. Si los animales desarrollan la forma crónica de la enfermedad, se puede generar un síndrome de cardiomiopatía dilatada debido al daño en tejido cardiaco el cuál cursa con signos como ascitis, arritmias, intolerancia al ejercicio, hepatomegalia, esplenomegalia, muerte súbita, entre otros (Kjos et al., 2008; Meyers et al., 2017; Sykes \& Greene, 2013). Estos síntomas también son comunes a otras enfermedades infecciosas, neoplásicas o degenerativas en caninos(Ettinger et al., 2017); no obstante es necesario considerar los signos de tripanosomiasis asociados con insuficiencia cardiaca, como diferencial en el proceso de diagnóstico de estos pacientes. A pesar de que no se puede asegurar que en todos los casos la cardiomiopatía fuera la causa principal de la muerte, sí es posible inferir que pudo haber contribuido al desarrollo de algunas de las patologías y signos clínicos presentados por los caninos. El diagnóstico post mortem de los casos de caninos infectados con $T$. cruzi se dificulta ya que muy pocos animales son sometidos a necropsia y estudio histopatológico debido ya sea a razones económicas o bien a la falta de interés por determinar la causa exacta de muerte por parte del médico tratante y/o los propietarios. Así mismo, en los casos en los que sí se realiza el estudio post mortem, no siempre es posible la observación de pseudoquistes con amastigotos en el examen histológico por lo que la aplicación de pruebas moleculares para detectar material genético puede contribuir de forma importante al diagnóstico. La identificación clínica y/o post mortem de caninos con tripanosomiasis posee una gran relevancia no sólo médico veterinaria, sino también en salud pública. Confirmar un caso canino puede ser de gran utilidad en la investigación y documentación de lugares donde podrían estar los vectores infectados con el agente y en la toma de medidas de prevención de la enfermedad de Chagas tanto en caninos como en seres humanos (Castillo-Neyra et al., 2015). La enfermedad de Chagas en humanos en Costa Rica es de reporte obligatorio y la sospecha de enfermedad o la presencia de vectores en las viviendas debe de llevar un seguimiento por parte de las autoridades en salud para la evaluación de los riesgos de infección en humanos y para la eliminación del vector de las viviendas (Norma de atención integral de la enfermedad de Chagas 2012). Por lo anterior, es responsabilidad de los médicos veterinarios considerar el enfoque de Una Salud al lidiar con enfermedades zoonóticas e informar apropiadamente a los propietarios acerca de la tripanosomiasis canina, su manejo médico y control del vector, así como los potenciales riesgos para los habitantes de las viviendas y sus mascotas. A su vez, debe de haber un trabajo conjunto y coordinado con las autoridades en salud humana sobre los casos caninos nuevos que se identifican para realizar una evaluación y manejo integral de las poblaciones humanas en riesgo. Por esta razón y dada la dificultad de identificar los casos clínicos de tripanosomiasis canina, se recomienda a los médicos de la práctica clínica de especies menores, actualizar conocimientos sobre la epidemiología de esta enfermedad y realizar exámenes electrocardiográficos y serológicos que apoyen el diagnóstico en los casos de animales con cardiopatías, insuficiencia cardiaca congestiva y anormalidades en el ritmo cardiaco o que procedan de zonas endémicas conocidas (Eloy \& Lucheis, 2009). Se enfatiza la responsabilidad del médico veterinario de informar a los propietarios sobre la posible etiología chagásica y sus implicaciones para la salud animal y humana y así propiciar la realización de estudios post mortem y/o prueba de PCR a aquellos caninos que mueran con la sintomatología anteriormente descrita (y sin identificación de una patología primaria) y casos de animales que sufran muerte súbita. El 
presente estudio destaca el desafío del diagnóstico de la tripanosomiasis canina en la práctica veterinaria.

\section{Conclusiones}

La aplicación de la prueba de PCR fue de gran utilidad para identificar casos de tripanosomiasis canina post mortem en caninos sin diagnóstico clínico, con muerte súbita con y sin evidencia histológica del agente. Se demostró la presencia de $\mathrm{ADN}_{\mathrm{k}}$ de T. cruzi en todos los caninos estudiados. Es importante sensibilizar al médico veterinario en la búsqueda de actualización continua sobre esta enfermedad endémica en Costa Rica y en la responsabilidad del trabajo conjunto con las autoridades de salud para la prevención de la tripanosomiasis en nuestro país.

\section{Conflicto de intereses}

Los autores declaran que no existe ningún conflicto de interés potencial en esta publicación.

\section{Referencias}

Avila, H. A., Pereira, J. B., Thiemann, O., De Paiva, E., DeGrave, W., Morel, C. M., \& Simpson, L. (1993). Detection of Trypanosoma cruzi in blood specimens of chronic chagasic patients by polymerase chain reaction amplification of kinetoplast minicircle DNA: Comparison with serology and xenodiagnosis. Journal of Clinical Microbiology, 31(9), 2421-2426. https://doi.org/10.1128/JCM.31.9.2421-2426.1993

Balan, L. U., Yerbes, I. M., Piña, M. A. N., Balmes, J., Pascual, A., Hernández, O., Lopez, R., \& Monteón, V. (2011). Higher seroprevalence of Trypanosoma cruzi infection in dogs than in humans in an urban area of Campeche, Mexico. Vector Borne and Zoonotic Diseases (Larchmont, N.Y.), 11(7), 843-844. https://doi.org/10.1089/vbz.2010.0039

Barr, S. C., Simpson, R. M., Schmidt, S. P., Bunge, M. M., Authement, J. M., \& Lozano, F. (1989). Chronic dilatative myocarditis caused by Trypanosoma cruzi in two dogs. Journal of the American Veterinary Medical Association, 195(9), 1237-1241.

Barr, Stephen C. (2009). Canine Chagas' disease (American trypanosomiasis) in North America. The Veterinary Clinics of North America. Small Animal Practice, 39(6), 1055-1064, v-vi. https://doi. org/10.1016/j.cvsm.2009.06.004

Barrera, Y. K., Guevara, J. M., Pavía, P. X., Montilla, M., Nicholls, R. S., Parra, E., \& Puerta, C. J. (2008). Evaluación de las pruebas de PCR TcH2AF-R y S35-S36 para la detección de Trypanosoma cruzi en tejido cardiaco de ratón. Biomédica, 28(4), 616-626. https:// doi.org/10.7705/biomedica.v28i4.68

Bonilla, M. C., Castro-Vásquez, R. M., Herrero-Acosta, M. V., Urbina-Villalobos, A., \& Dolz, G. (2019). Canine trypanosomiasis in an endemic Costa Rican community: Demonstration of the active infection cycle. Veterinary Parasitology: Regional Studies and Reports, 17, 100307. https://doi.org/10.1016/j.vprsr.2019.100307

Caliari, M. V., do Pilar Machado, R., de Lana, M., Caja, R. A. F., Carneiro, C. M., Bahia, M. T., dos Santos, C. A. B., Magalhaes, G. A., Sampaio, I. B. M., \& Tafuri, W. L. (2002). Quantitative analysis of cardiac lesions in chronic canine chagasic cardiomyopathy. Revista Do Instituto De Medicina Tropical De Sao 
Paulo, 44(5), 273-278. https://doi.org/10.1590/s0036-46652002000500008

Cantillo-Barraza, O., Garcés, E., Gómez-Palacio, A., Cortés, L. A., Pereira, A., Marcet, P. L., Jansen, A. M., \& Triana-Chávez, O. (2015). Eco-epidemiological study of an endemic Chagas disease region in northern Colombia reveals the importance of Triatoma maculata (Hemiptera: Reduviidae), dogs and Didelphis marsupialis in Trypanosoma cruzi maintenance. Parasites Eீ Vectors, 8, 482. https://doi. org/10.1186/s13071-015-1100-2

Castillo-Neyra, R., Chou-Chu, L., Quispe-Machaca, V., Ancca-Juarez, J., Malaga Chavez, F. S., Mazuelos, M. B., Naquira, C., Bern, C., Gilman, R. H., \& Levy, M. Z. (2015). The potential of canine sentinels for reemerging Trypanosoma cruzi transmission. Preventive veterinary medicine, 120(0), 349-356. https://doi.org/10.1016/j.prevetmed.2015.04.014

Eloy, L. J., \& Lucheis, S. B. (2009). Canine trypanosomiasis: Etiology of infection and implications for public health. Journal of Venomous Animals and Toxins Including Tropical Diseases, 15(4), 589-611. https://doi.org/10.1590/S1678-91992009000400002

Ettinger, S. J., Feldman, E. C., \& Cote, E. (Eds.) (2017). Textbook of Veterinary Internal Medicine (8. ${ }^{a}$ ed.). Elsevier Health Sciences.

Ferrer, E. (2015). Técnicas moleculares para el diagnóstico de la enfermedad de Chagas. Saber, 27(3), 359-371. Recuperado en 15 de abril de 2021, de http://ve.scielo.org/scielo.php?script=sci_arttext\&pid=S1315$\underline{01622015000300002 \& \operatorname{lng}=e s \& t \operatorname{lng}=e s}$

Greer, C. E., Lund, J. K., \& Manos, M. M. (1991). PCR amplification from paraffin-embedded tissues: Recommendations on fixatives for long-term storage and prospective studies. PCR Methods and Applications, 1(1), 46-50. https://doi.org/10.1101/gr.1.1.46

Hodo, C. L., Bañuelos, R. M., Edwards, E. E., Wozniak, E. J., \& Hamer, S. A. (2020). Pathology and discrete typing unit associations of Trypanosoma cruzi infection in coyotes (Canis latrans) and raccoons (Procyon lotor) of texas, usa. Journal of Wildlife Diseases, 56(1), 134-144. Recuperado en 15 de abril de 2021, de https://www.ncbi.nlm.nih.gov/pmc/articles/PMC7594014/pdf/nihms-1639408.pdf

Jones, E. M., Colley, D. G., Tostes, S., Lopes, E. R., Vnencak-Jones, C. L., \& McCurley, T. L. (1993). Amplification of a Trypanosoma cruzi DNA sequence from inflammatory lesions in human chagasic cardiomyopathy. The American Journal of Tropical Medicine and Hygiene, 48(3), 348-357. https://doi. org/10.4269/ajtmh.1993.48.348

Kjos, S. A., Snowden, K. F., Craig, T. M., Lewis, B., Ronald, N., \& Olson, J. K. (2008). Distribution and characterization of canine Chagas disease in Texas. Veterinary Parasitology, 152(3-4), 249-256. https:// doi.org/10.1016/j.vetpar.2007.12.021

Lizundia, R., Picado, A., Cordero, M., Calderón, A., Deborggraeve, S., Montenegro, V. M., \& Urbina, A. (2014). Molecular and serological rapid tests as markers of Trypanosoma cruzi infection in dogs in Costa Rica. Tropical Parasitology, 4(2), 111-114.https://doi.org/10.4103/2229-5070.138539

Mena-Marín, A. L., Zeledón, R., Morales, J. A., Pereira, M., \& Urbina, A. (2012). Sex influence on the 
susceptibility of Swiss mice to Trypanosoma cruzi. Boletin de Malariologia y Salud Ambiental, 52(2), 233-244. Scopus. Recuperado en 25 de marzo de 2021, de http://ve.scielo.org/scielo.php?script=sci arttext\&pid=S1690-46482012000200005\&lng=es\&tlng=es

Meyers, A. C., Meinders, M., \& Hamer, S. A. (2017). Widespread Trypanosoma cruzi infection in government working dogs along the Texas-Mexico border: Discordant serology, parasite genotyping and associated vectors. PLoS Neglected Tropical Diseases, 11(8), e0005819. https://doi.org/10.1371/ journal.pntd.0005819

Molesan, A., Goodman, L., Ford, J., Lovering, S. J., \& Kelly, K. (2019). The Causes of Canine Myocarditis and Myocardial Fibrosis Are Elusive by Targeted Molecular Testing: Retrospective Analysis and Literature Review. Veterinary Pathology, 56(5), 761-777. https://doi.org/10.1177/0300985819839241

Montenegro, V. M., Jiménez, M., Dias, J. P., \& Zeledón, R. (2002). Chagas Disease in Dogs from Endemic Areas of Costa Rica. Memórias Do Instituto Oswaldo Cruz, 97(4), 491-494. https://doi.org/10.1590/ $\underline{\text { S0074-02762002000400006 }}$

Moser, D. R., Kirchhoff, L. V., \& Donelson, J. E. (1989). Detection of Trypanosoma cruzi by DNA amplification using the polymerase chain reaction. Journal of Clinical Microbiology, 27(7), 1477-1482. https:// doi.org/10.1128/JCM.27.7.1477-1482.1989

Rassi, A., Rassi, A., \& Marcondes de Rezende, J. (2012). American trypanosomiasis (Chagas disease). Infectious Disease Clinics of North America, 26(2), 275-291. https://doi.org/10.1016/j.idc.2012.03.002

Rojas-Jiménez, J., Morales-Acuña, J. A., Argüello-Sáenz, M., Acevedo-González, S. E., Yabsley, M. J., \& Urbina-Villalobos, A. (2021). Histopathological findings of infections caused by canine distemper virus, Trypanosoma cruzi, and other parasites in two free-ranging White-nosed Coatis Nasua narica (Carnivora: Procyonidae) from Costa Rica. Journal of Threatened Taxa, 13(1), 17521-17528. https:// doi.org/10.11609/jott.5907.13.1.17521-17528

Saldaña, A., Calzada, J. E., Pineda, V., Perea, M., Rigg, C., González, K., Santamaria, A. M., Gottdenker, N. L., \& Chaves, L. F. (2015). Risk factors associated with Trypanosoma cruzi exposure in domestic dogs from a rural community in Panama. Memórias Do Instituto Oswaldo Cruz, 110(7), 936-944. https:// doi.org/10.1590/0074-02760150284

Sykes, J. E., \& Greene, C. E. (Eds.). (2013). Infectious Diseases of the Dog and Cat. (4. ${ }^{a}$ ed.). Elsevier Health Sciences.

Tafuri, W. L. (1999). Immunopathology of Chagas disease-A historical overview. Memórias Do Instituto Oswaldo Cruz, 94, 247-248. https://doi.org/10.1590/S0074-02761999000700040

Vallejo, G.A., Guhl, F., Chiari, E., \& Macedo, A.M. (1999). Species specific detection of Trypanosoma cruzi and Trypanosoma rangeli in vector and mammalian hosts by polymerase chain reaction amplification of kinetoplast minicircle DNA. Acta Tropica 72: 203-212. https://doi.org/10.1016/S0001$\underline{706 X(98) 00085-0}$

Vallejo, G.A., Suárez, J., Olaya, J.L., Gutierrez, S.A., \& Carranza, J.C. (2015). Trypanosoma rangeli: un 
protozoo infectivo y no patógeno para el humano que contribuye al entendimiento de la transmisión vectorial y la infección por Trypanosoma cruzi, agente causal de la enfermedad de Chagas. Revista de La Academia Colombiana de Ciencias Exactas, Físicas y Naturales 39(150), 111-122. https://doi. org/10.18257/raccefyn.143

Vitt, J. P., Saunders, A. B., O’Brien, M. T., Mansell, J., Ajithdoss, D. K., \& Hamer, S. A. (2016). Diagnostic Features of Acute Chagas Myocarditis with Sudden Death in a Family of Boxer Dogs. Journal of Veterinary Internal Medicine, 30(4), 1210-1215. https://doi.org/10.1111/jvim.13967

Williams, J. T., Mubiru, J. N., Schlabritz-Loutsevitch, N. E., Rubicz, R. C., VandeBerg, J. L., Dick, E. J., \& Hubbard, G. B. (2009). Polymerase chain reaction detection of Trypanosoma cruzi in Macaca fascicularis using archived tissues. The American Journal of Tropical Medicine and Hygiene, 81(2), 228-234. Recuperado el 24 de abril de 2021, en https://www.ncbi.nlm.nih.gov/pmc/articles/ PMC2740910/pdf/nihms135175.pdf

Zachary, J. F., \& McGavin, M. D. (Eds.) (2016). Pathologic Basis of Veterinary Disease Expert Consult. (6. ${ }^{a}$ ed.) Elsevier Health Sciences.

Zuriaga, M. Á., Blandón-Naranjo, M., Valerio-Campos, I., Salas, R., Zeledón, R., \& Bargues, M. D. (2012). Molecular characterization of Trypanosoma cruzi and infection rate of the vector Triatoma dimidiata in Costa Rica. Parasitology Research, 111(4), 1615-1620. https://doi.org/10.1007/s00436-012-3000-0 